\title{
D- $\beta$-Hydroxybutyrate rescues mitochondrial respiration and mitigates features of Parkinson disease
}

\author{
Kim Tieu, ${ }^{1}$ Celine Perier, ${ }^{1}$ Casper Caspersen, ${ }^{2}$ Peter Teismann, ${ }^{1}$ Du-Chu Wu, ${ }^{1}$ \\ Shi-Du Yan, ${ }^{2,3}$ Ali Naini, ${ }^{1}$ Miquel Vila, ${ }^{1}$ Vernice Jackson-Lewis, ${ }^{1}$ \\ Ravichandran Ramasamy, ${ }^{2}$ and Serge Przedborski ${ }^{1,3,4}$ \\ ${ }^{1}$ Department of Neurology, \\ ${ }^{2}$ Department of Surgery, \\ ${ }^{3}$ Department of Pathology, and \\ ${ }^{4}$ The Center for Neurobiology and Behavior, Columbia University, New York, New York, USA
}

\begin{abstract}
Parkinson disease (PD) is a neurodegenerative disorder characterized by a loss of the nigrostriatal dopaminergic neurons accompanied by a deficit in mitochondrial respiration. 1-Methyl-4-phenyl1,2,3,6-tetrahydropyridine (MPTP) is a neurotoxin that causes dopaminergic neurodegeneration and a mitochondrial deficit reminiscent of PD. Here we show that the infusion of the ketone body $\mathrm{D}-\beta$-hydroxybutyrate $(\mathrm{D} \beta \mathrm{HB})$ in mice confers partial protection against dopaminergic neurodegeneration and motor deficits induced by MPTP. These effects appear to be mediated by a complex IIdependent mechanism that leads to improved mitochondrial respiration and ATP production. Because of the safety record of ketone bodies in the treatment of epilepsy and their ability to penetrate the blood-brain barrier, $\mathrm{D} \beta \mathrm{HB}$ may be a novel neuroprotective therapy for PD.
\end{abstract}

J. Clin. Invest. 112:892-901 (2003). doi:10.1172/JCI200318797.

\section{Introduction}

Parkinson disease (PD) is the second most common neurodegenerative disease after Alzheimer disease (1). PD is clinically characterized by disabling motor abnormalities, which include tremor, muscle stiffness, paucity of voluntary movements, and postural instability (2), and its main neuropathological feature is the loss of substantia nigra pars compacta (SNpc) dopaminergic neurons (3).

While PD is a sporadic condition of uncertain etiology (2), several lines of evidence suggest that a defect in oxidative phosphorylation contributes to its pathogenesis. For instance, 1-methyl-4-phenyl-1,2,3,6-tetrahydropyridine (MPTP), a neurotoxin that blocks complex I (NADH-ubiquinone oxidoreductase) of the mitochondrial electron transport chain (4), recapitulates in humans the hallmarks of PD (5). Furthermore, reduction in complex I activity has been reported in PD tissues (reviewed in ref. 6). This defect is not

Received for publication April 30, 2003, and accepted in revised form July 17, 2003

Address correspondence to: Serge Przedborski, BB-307, Columbia University, 650 W. 168th Street, New York, New York 10032, USA. Phone: (212) 305-1540; Fax: (212) 305-5450; E-mail: SP30@columbia.edu.

Conflict of interest: The authors have declared that no conflict of interest exists.

Nonstandard abbreviations used: Parkinson disease (PD); substantia nigra pars compacta (SNpc); 1-methyl-4-phenyl$1,2,3,6$-tetrahydropyridine (MPTP); D- $\beta$-hydroxybutyrate (D $\beta \mathrm{HB})$; L-B-hydroxybutyrate (L $\beta \mathrm{HB})$; 3-nitropropionic acid (3-NP); tyrosine hydroxylase (TH); 1-methyl-4-phenylpyridinium $\left(\mathrm{MPP}^{+}\right)$; carbonylcyanide $p$-trifluoromethoxyphenylhydrazone (FCCP); transmembrane potential $\left(\Delta \psi_{\mathrm{m}}\right)$; arbitrary fluorescence unit (AFU); dihydroxyphenylacetic acid (DOPAC); homovanillic acid (HVA); reactive oxygen species (ROS); tricarboxylic acid (TCA). confined only to the brain (7), since low complex I activity has also been found in platelets from PD patients $(8,9)$ and in cybrid cells engineered to contain mitochondria derived from platelets of patients suffering from $\mathrm{PD}(10)$.

$\mathrm{D}-\beta$-Hydroxybutyrate $(\mathrm{D} \beta \mathrm{HB})$ is a ketone body produced by hepatocytes and, to a lesser extent, by astrocytes (11). It is an alternative source of energy in the brain when glucose supply is depleted such as during starvation (12). In vitro $\mathrm{D} \beta \mathrm{HB}$ prevents neuronal damage seen following glucose deprivation (13) and mitochondrial poison exposure (14). Herein, we show that $\mathrm{D} \beta \mathrm{HB}$ infusion protects $\mathrm{SNpc}$ dopaminergic neurons against MPTP in a dose-dependent and stereospecific manner and prevents the development of PD-like motor abnormalities in mice. We also provide in vivo and in vitro evidence that $\mathrm{D} \beta \mathrm{HB}$ protects not by alleviating MPTP-related complex I inhibition, but by enhancing oxidative phosphorylation via a mechanism dependent on mitochondrial complex II (succinateubiquinone oxidoreductase).

\section{Methods}

Animals and treatment. All animals were 8- to 10-week-old male C57BL mice (Charles River Laboratories, Wilmington, Massachusetts, USA). Mice were divided into four groups: vehicle (i.e., saline), D $\beta \mathrm{HB}$, L-hydroxybutyrate $(\mathrm{L} \beta \mathrm{HB})$, and $\mathrm{D} \beta \mathrm{HB}$ plus 3-nitropropionic acid (3-NP). Vehicle, D $\beta \mathrm{HB}(1.6,0.8$, or $0.4 \mathrm{mmol} / \mathrm{kg} / \mathrm{d}$ in saline, $\mathrm{pH}$ 7.4; Sigma-Aldrich, St. Louis, Missouri, USA), and $\mathrm{L} \beta \mathrm{HB}(1.6 \mathrm{mmol} / \mathrm{kg} / \mathrm{d}$ in saline, $\mathrm{pH}$ 7.4; SigmaAldrich) were administered subcutaneously $(1 \mu \mathrm{l} / \mathrm{h})$ using Alzet mini-osmotic pumps (DURECT Corp., Cupertino, California, USA). 3-NP (Sigma-Aldrich; 
$15 \mathrm{mg} / \mathrm{kg}$, in $0.1 \mathrm{M}$ PBS adjusted to $\mathrm{pH} 7.4$ ) was given intraperitoneally 2 hours before the implantation on the first day and then once a day until the animals were sacrificed. This dosage of 3-NP was selected to inhibit complex II but not to induce cell loss. After surgery, animals were allowed to rest for 1 day. Each mouse was then randomly assigned to receive four intraperitoneal injections of either MPTP $(18 \mathrm{mg} / \mathrm{kg}$ of free base in saline; Sigma-Aldrich) or saline at 2-hour intervals.

Tyrosine bydroxylase immunostaining and quantitative morphology. Seven days after the last MPTP injection, mice were killed and their brains were processed for immunohistochemical studies. Sections $(30 \mu \mathrm{m})$ were incubated with a polyclonal anti-tyrosine hydroxylase (TH; 1,000 dilution; Calbiochem-Novabiochem Corp., San Diego, California, USA) for 48 hours at $4^{\circ} \mathrm{C}$. Biotinylated secondary antibodies followed by avidinbiotin complex were used. Immunoreactivity was visualized by incubation in 3,3'-diaminobenzidine/glucose/glucose oxidase. Total numbers of TH-positive neurons in SNpc were counted stereologically using the optical fractionator method (15). Striatal OD of TH immunostaining, determined by the Scion Image program (Scion Corp., Frederick, Maryland, USA), was used as an index of striatal density of TH innervation (16). The concentration of anti-TH antibody and 3,3'-diaminobenzidine (DAB) and the duration of incubation of striatal sections in $\mathrm{DAB}$ were optimized to fall within the linear range of the plot of the immunostaining intensities and the scanned ODs.

Measurement of $D \beta H B$ and succinate levels. At different time points after the implantation of the osmotic pumps, blood was collected from tails, and brains were quickly removed, freeze-clamped under liquid nitrogen, and stored at $-80^{\circ} \mathrm{C}$. Frozen tissues were treated with perchloric acid and neutralized with sodium hydroxide as previously described (17). Both $\mathrm{D} \beta \mathrm{HB}$ and succinate were measured spectrophotometrically at $340 \mathrm{~nm}$ using commercial kits from Sigma-Aldrich and from Roche Molecular Biochemicals (Indianapolis, Indiana, USA) respectively, following the manufacturers' instructions. Measurement of striatal 1-methyl-4-phenylpyridinium levels. Mice infused with either saline or D $\beta \mathrm{HB}(1.6 \mathrm{mmol} /$ $\mathrm{kg} / \mathrm{d})$ were injected with MPTP $(18 \mathrm{mg} / \mathrm{kg})$ as described above and killed 90 minutes after the fourth injection. HPLC with UV detection (295 nm) was used to measure striatal 1-methyl-4-phenylpyridinium (MPP+) levels as previously described (18) with the following modifications: a reverse-phase Altima C18 column (Alltech Associates Inc., Deerfield, Illinois, USA) and a mobile phase consisting of $89 \% 50 \mathrm{mM} \mathrm{KH}_{2} \mathrm{PO}_{4}$ and $11 \%$ acetonitrile were used. Data represent mean \pm SEM of five mice per group.

Synaptosomal uptake of $M P P^{+}$. Striata were dissected out from naive mice and processed for uptake experiments as described previously (19) with a few modifications. Briefly, striata were homogenized in $0.32 \mathrm{M}$ sucrose and centrifuged at $700 \mathrm{~g}, 4^{\circ} \mathrm{C}$, for 10 minutes. The supernatant was removed and centrifuged at 27,000 $\mathrm{g}$ for 30 minutes. The resulting synaptosomal pellet was suspended at $1.2 \mathrm{mg} / \mathrm{ml}$ (original wet weight) in KrebsRinger phosphate buffer ( $\mathrm{pH}$ 7.4). The uptake reaction was initiated by addition of $0.6 \mathrm{mg}$ of synaptosomes to tubes containing $\left[{ }^{3} \mathrm{H}\right] \mathrm{MPP}^{+}(\sim 4 \mathrm{nM}, \sim 800,000$ degradations per minute, specific activity $31.6 \mathrm{Ci} / \mathrm{mmol}$; American Radiolabeled Chemicals Inc., St. Louis, Missouri, USA) in the absence or presence of $\mathrm{D} \beta \mathrm{HB}$ (up to $5 \mathrm{mM}$ ) at $37^{\circ} \mathrm{C}$ for 6 minutes. Nonspecific uptake was assessed in the presence of $10 \mu \mathrm{M}$ mazindol. Data represent mean \pm SEM of three mice per group.

Isolation of brain mitochondria. Brains from C57BL mice were homogenized in isolation buffer $(225 \mathrm{mM}$ mannitol, $75 \mathrm{mM}$ sucrose, $1 \mathrm{mM}$ EGTA, $5 \mathrm{mM}$ HEPES, and $2 \mathrm{mg} / \mathrm{ml}$ fat-free BSA) using a motorized Dounce homogenizer with eight up-and-down strokes. The homogenate was centrifuged at $1,000 \mathrm{~g}$ for 10 minutes, and the resulting supernatant was layered onto $5 \mathrm{ml}$ of $7.5 \%$ Ficoll medium on top of $5 \mathrm{ml}$ of $10 \%$ Ficoll medi$\mathrm{um}$ and centrifuged at 79,000 $\mathrm{g}$ for 30 minutes (the Ficoll medium contained $0.3 \mathrm{M}$ sucrose, $50 \mu \mathrm{M}$ EGTA, and $10 \mathrm{mM}$ HEPES). The mitochondrial pellet was resuspended in isolation buffer. Protein concentrations were determined by the bicinchoninic assay (Pierce Chemical Co., Rockford, Illinois, USA) method with BSA as a standard protein.

Mitochondrial accumulation of $M P P^{+}$. Brain mitochondria were isolated and resuspended in buffer as described previously (20) but with a few modifications. The uptake reaction was initiated by addition of $0.6 \mathrm{mg}$ of mitochondria to tubes containing $5 \mu \mathrm{M}\left[{ }^{3} \mathrm{H}\right] \mathrm{MPP}^{+}$and 45 $\mu \mathrm{M} \mathrm{MPP}^{+}$in the absence or presence of $\mathrm{D} \beta \mathrm{HB}$ (up to 5 $\mathrm{mM}$ ) at $25^{\circ} \mathrm{C}$ for 3 minutes. Nonspecific uptake was assessed in the presence of $5 \mu \mathrm{M}$ carbonylcyanide $p$-trifluoromethoxyphenylhydrazone (FCCP). Data represent mean \pm SEM of four or five mice per group.

Polarography. Brain mitochondria were suspended in respiration buffer consisting of $225 \mathrm{mM}$ mannitol, 75 mM sucrose, $10 \mathrm{mM} \mathrm{KCl,} 5 \mathrm{mM}$ HEPES, $5 \mathrm{mM} \mathrm{K}_{2} \mathrm{HPO}_{4}$, and freshly added $1 \mathrm{mg} / \mathrm{ml}$ defatted BSA at $30^{\circ} \mathrm{C}$, and oxygen-consumption rates were measured in a closedchamber cuvette with a mini-stirring bar using a Clarktype electrode (Hansatech Instruments Ltd., Norfolk, United Kingdom). For each reading, $300 \mu \mathrm{g}$ protein was used in a final 1-ml respiration buffer, and all mitochondria preparations had an average respiratory control ratio of at least 5 when $10 \mathrm{mM}$ glutamate and $5 \mathrm{mM}$ malate were used as NADH-linked substrates.

ATP measurements. Samples were prepared under conditions identical to those of polarographical study. Mitochondria suspended in respiration buffer were incubated in the presence or absence of different substrates or inhibitors using the same incubation times as those of polarographical study. Where 3-NP was used, it was added from the beginning with $\mathrm{MPP}^{+}$( 5 minutes) or rotenone (2.5 minutes) to mitochondria before the addition of $\mathrm{D} \beta \mathrm{HB}$. When the reaction was stopped, mitochondrial suspension from the cuvette was lysed in an equal volume of lysis buffer from the ATP biolumi- 
nescence assay kit (Roche Molecular Biochemicals), and the content of ATP was measured according to the manufacturer's instructions. Light emitted from luciferasemediated reaction was captured in a tube luminometer and calculated from a log-log plot of the standard curve of known ATP concentrations.

Measurements of mitochondrial $\mathrm{H}_{2} \mathrm{O}_{2}$ production. Samples were prepared under conditions identical to those of polarographical study. Mitochondria suspended in respiration buffer were incubated in the presence or absence of different substrates or inhibitors using the same incubation times as those of polarographical study. Phenazine methosulfate $(0.1 \mathrm{mM})$ was used to oxidize NADH (21). Hydrogen peroxide, converted from superoxide by manganese-superoxide dismutase, was measured using $5 \mu \mathrm{M}$ Amplex red (Molecular Probes, Eugene, Oregon, USA) and 5 U/ml HRP. Fluorescence was detected by a Perkin-Elmer (Boston, Massachusetts, USA) LS55 spectrofluorometer with an excitation wavelength of $550 \mathrm{~nm}$ (slit $1.5 \mathrm{~nm}$ ) and an emission wavelength of $585 \mathrm{~nm}$ (slit $3 \mathrm{~nm}$ ). $\mathrm{H}_{2} \mathrm{O}_{2}$ production was calculated from a standard curve generated from known concentrations of $\mathrm{H}_{2} \mathrm{O}_{2}$.

Measurements of mitochondrial transmembrane potential. Safranine, a cationic fluorescence dye accumulated and quenched inside energized mitochondria $(22,23)$ was used to measure transmembrane potential $\left(\Delta \psi_{\mathrm{m}}\right)$. Mitochondria were incubated with $10 \mathrm{mM}$ glutamate, $5 \mathrm{mM}$ malate, and $5 \mu \mathrm{M}$ safranine (Sigma-Aldrich) in respiration buffer 5 minutes before $5 \mathrm{mM}$ D $\beta \mathrm{HB}$ was added, and $\Delta \psi_{\mathrm{m}}$ was monitored for an additional 5 minutes. FCCP $(5 \mu \mathrm{M})$ was used as a positive control to collapse $\Delta \psi_{\mathrm{m}}$. Fluorescence was detected by a PerkinElmer LS55 spectrofluorometer with an excitation wavelength of $495 \mathrm{~nm}$ (slit $3 \mathrm{~nm}$ ) and an emission wavelength of $586 \mathrm{~nm}$ (slit $5 \mathrm{~nm}$ ). Data are reported in arbitrary fluorescence units (AFUs).

Complex I activity. Largely based on protocols described by Birch-Machin and Turnbull (24), brain mitochondria were lysed by freeze-thawing in hypotonic buffer $(25$ $\mathrm{mM} \mathrm{KH}_{2} \mathrm{PO}_{4}$ [pH 7.2], $5 \mathrm{mM} \mathrm{MgCl}_{2}$ ) three times. To initiate the reaction, $50 \mu \mathrm{g}$ mitochondria were added to the assay buffer (hypotonic buffer containing $65 \mu \mathrm{M}$ ubiquinone $_{1}, 130 \mu \mathrm{M} \mathrm{NADH}, 2 \mu \mathrm{g} / \mathrm{ml}$ antimycin $\mathrm{A}$, and $2.5 \mathrm{mg} / \mathrm{ml}$ defatted BSA) in the absence or presence of different concentrations of rotenone $(2.5-15 \mu \mathrm{M})$ or $\mathrm{MPP}^{+}(10-30 \mathrm{mM})$. The oxidation of NADH by complex I was monitored at $340 \mathrm{~nm}$ spectrophotometrically for 3 minutes at $30^{\circ} \mathrm{C}$ prior to the addition of rotenone $(2$ $\mu \mathrm{g} / \mathrm{ml})$, after which the activity was measured for an additional 3 minutes. The difference in rate before and after the addition of rotenone $(2 \mu \mathrm{g} / \mathrm{ml})$ was used to calculate complex I activity.

Complex II histochemistry. Animals were injected intraperitoneally with either saline or $3-\mathrm{NP}(15 \mathrm{mg} / \mathrm{kg})$ once daily for 8 days, the same regimen used in the animals that received $\mathrm{D} \beta \mathrm{HB}$. As described previously (25), animals were perfused with PBS containing $10 \%$ glycerol. Brains were rapidly removed, frozen in dry ice-cooled isopentane, and stored at $-80^{\circ} \mathrm{C}$. Brains were sectioned at $20 \mu \mathrm{m}$ throughout the entire nigra and striatum. Sections were mounted onto glass microscope slides, and complex II activity was revealed by incubation of sections at $37^{\circ} \mathrm{C}$ for 20 minutes in 50 $\mathrm{mM}$ phosphate buffer ( $\mathrm{pH} 7.6)$ containing $50 \mathrm{mM}$ succinate as a substrate and $0.3 \mathrm{mM}$ Nitroblue tetrazolium (NBT) as an electron acceptor.

Immunoblots. Total tissue proteins from ventral midbrains of MPTP- and saline-treated mice were isolated as described previously (26), and $20 \mu \mathrm{g}$ proteins were separated on $12 \%$ SDS-PAGE. Membranes were blotted with polyclonal anti- $\beta$-hydroxybutyrate dehydrogenase (1:100; a generous gift from Andrew Marks, Columbia University, New York, New York, USA) and monoclonal anti$\beta$-actin $(1: 5,000)$ overnight at $4^{\circ} \mathrm{C}$. Secondary antibodies conjugated with HRP were used. Bands of interest were analyzed and quantified using FluorChem 8800 (Alpha Innotech Corp., San Leandro, California, USA).

Rotarod performance. The Economex system (Columbus Instruments, Columbus, Ohio, USA), consisting of four rotating rods of $3 \mathrm{~cm}$ diameter in separated compartments, enables four mice to be recorded simultaneously. Seven days after MPTP or saline injections, implanted pumps containing $1.6 \mathrm{mmol} / \mathrm{kg} / \mathrm{d} \mathrm{D} \beta \mathrm{HB}$ were removed, and mice (4-13 animals per group) were allowed to recover from surgery and dehydration for an additional 7 days. On the testing day, animals were first pretrained three times ( 1 hour apart) using an accelerating mode. After these training sessions, the time on the rod, with a maximum recording time of 240 seconds, was recorded for successive rotational speeds $(15,18,21$, $24,27,30,32,36$, and $40 \mathrm{rpm})$, and the overall rod performance (ORP) for each mouse was calculated by the trapezoidal method as the area under the curve in the plot of time on the rod versus rotation speed (27). To assess the responsiveness of the MPTP-related motor deficit to dopaminergic stimulation, mice were injected intraperitoneally with L-3,4-dihydroxyphenylalanine (L-DOPA) methyl ester/benserazide (100/25 mg/kg), and Rotarod performance was assessed 45 minutes later.

Measurement of dopamine and its metabolite levels in striatal and ventral midbrain tissues. Animals from the Rotarod study were sacrificed, and their striata and ventral midbrains were dissected out and stored at $-80^{\circ} \mathrm{C}$ until analysis. On the day of the assay, striatal and ventral midbrain tissues were sonicated in 50 and 10 volumes (wt/vol), respectively, of $0.1 \mathrm{M}$ perchloric acid containing $50 \mathrm{ng} / \mathrm{ml}$ dihydrobenzylamine as internal standard. After centrifugation at $15,000 \mathrm{~g}$ for 15 minutes at $4^{\circ} \mathrm{C}$, $20 \mu \mathrm{l}$ of supernatant was injected onto a C18 reversephase HR-80 catecholamine column (ESA Inc., Bedford, Massachusetts, USA). The mobile phase consisted of $94 \% 50 \mathrm{mM}$ sodium phosphate/0.2 $\mathrm{mM}$ EDTA/1.2 mM heptanesulfonic acid ( $\mathrm{pH} 3.2$ ) solution and $6 \%$ methanol. The flow rate was $1.5 \mathrm{ml} / \mathrm{min}$. Peaks were detected by an ESA 8 Channel CoulArray system. Data were collected and processed using the CoulArray data analysis program (version 1.12). 

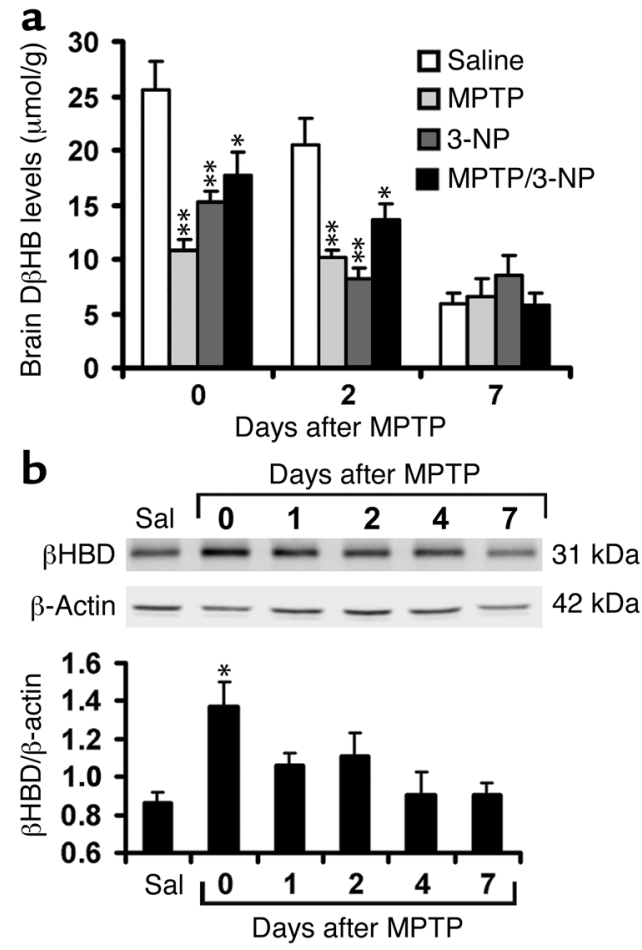

Statistical analysis. All values are expressed as mean \pm SEM. Differences between means were analyzed using oneway ANOVA followed by Newman-Keuls post-hoc testing for pairwise comparison. The null hypothesis was rejected when $P$ was greater than 0.05 .

\section{Results}

$M P T P$ upregulates $D \beta H B$-metabolizing enzyme and increases utilization of $D \beta H B$ in the brain. To assure sustained high tissue levels of $\mathrm{D} \beta \mathrm{HB}$ during the experiment, this short-half-life (28) compound was infused subcutaneously at a dose of $1.6 \mathrm{mmol} / \mathrm{kg} / \mathrm{d}$ for the entire 7 days. This regimen seemed well tolerated and yielded a stable plasma level of approximately $0.9 \mathrm{mM}$ throughout the 7-day period. Likewise, brain $\mathrm{D} \beta \mathrm{HB}$ levels in mice intoxicated with MPTP did not significantly change throughout the experiment (Figure 1a). Brain $\mathrm{D} \beta \mathrm{HB}$ levels in mice that received saline instead of receiving MPTP, 3-NP, or both were significantly higher, at least at the beginning of the experiment (Figure 1a).

Circulating $\mathrm{D} \beta \mathrm{HB}$ readily crosses the blood-brain barrier and enters mitochondria, where it is metabolized by $\beta$-hydroxybutyrate dehydrogenase to acetoacetate; the latter is converted to acetyl-CoA, which feeds into the Krebs cycle (29). In saline-

\section{Figure 1}

Brain levels of $\mathrm{D} \beta \mathrm{HB}$ and $\beta$-hydroxybutyrate dehydrogenase ( $\beta \mathrm{HBD}$ ) under different treatments. (a) One day after implantation of pumps containing $\mathrm{D} \beta \mathrm{HB}$, animals were injected intraperitoneally with saline (Sal), MPTP, or 3-NP as described in Methods, and brain levels of $\mathrm{D} \beta \mathrm{HB}$ were measured at 0 days ( 90 minutes after the fourth injection), 2 days, and 7 days thereafter. The utilization of $\mathrm{D} \beta \mathrm{HB}$ was increased when cells were under metabolic stress induced by these toxins. $n=4-6 ;{ }^{*} P<0.05$ and ${ }^{*} P<0.01$ compared with the respective control saline groups. (b) Western blot analysis of ventral midbrains from MPTP-intoxicated mice shows upregulation of this enzyme as early as day $0 . n=4-5$ per group; ${ }^{*} P<0.05$ compared with the control saline group. $\beta$-Actin is used to normalize $\beta$ HBD values.

injected control mice, $\beta$-hydroxybutyrate dehydrogenase protein content in ventral midbrain (the brain region that contains the $\mathrm{SNpc}$ ) was detectable (Figure $1 \mathrm{~b}$ ). In MPTP-injected mice, $\beta$-hydroxybutyrate dehydrogenase protein content in ventral midbrain rose rapidly and remained elevated for 2 days after the last injection of MPTP (Figure 1b). These data suggest that MPTP-related cellular stress is associated with a $\beta$-hydroxybutyrate dehydrogenase upregulation, which in turn may facilitate utilization of $\mathrm{D} \beta \mathrm{HB}$ in the brain.

$D \beta H B$ attenuates MPTP-induced dopaminergic neurodegeneration. One day after implantation of pumps containing either vehicle or $\mathrm{D} \beta \mathrm{HB}$, mice were injected with MPTP. Seven days later, the brains of these animals were processed for quantification of dopaminergic cell bodies in the SNpc and of projecting dopaminergic fibers in the striatum using TH immunostaining. In saline-injected mice infused with either vehicle or $\mathrm{D} \beta \mathrm{HB}$, numbers of TH-positive neurons in the SNpc were identical (Table 1 ; Figure 2, a and $\mathrm{b}$ ), as were TH ODs in the striatum (Table 1; Figure 2, i and j). In MPTP-injected mice infused with vehicle, there was an approximately $70 \%$ loss of SNpc TH-positive neurons and an approximately $90 \%$ reduction of striatal TH ODs (Table 1; Figure 2, e and $\mathrm{m}$ ) compared with saline-injected controls (Table 1; Figure 2, a and i). In contrast, in MPTP-injected mice
Table 1

$\mathrm{TH}$ - and Nissl-positive neurons in SNpc and striatal TH density

\begin{tabular}{|c|c|c|c|c|c|}
\hline & MPTP & 3-NP & Nigral TH & Nigral Nissl & $\begin{array}{l}\text { Striatal TH } \\
\text { OD }(\times 100)\end{array}$ \\
\hline icle & - & - & $9,770 \pm 694$ & $15,525 \pm 930$ & $21.78 \pm 1.90$ \\
\hline $\mathrm{HB}(1.6 \mathrm{mmol} / \mathrm{kg} / \mathrm{d})$ & - & - & $9,293 \pm 590$ & $14,880 \pm 416$ & $23.76 \pm 2.10$ \\
\hline$-\mathrm{B}(1.6 \mathrm{mmol} / \mathrm{kg} / \mathrm{d})$ & - & - & $9,040 \pm 705$ & $12,987 \pm 1,274$ & $20.47 \pm 1.43$ \\
\hline icle & - & + & $8,933 \pm 1,040$ & $12,387 \pm 1,169$ & $23.11 \pm 4.43$ \\
\hline cle & + & - & $3,233 \pm 280$ & $6,445 \pm 380$ & $1.61 \pm 0.16$ \\
\hline icle & + & + & $2,600 \pm 654$ & $5,860 \pm 850$ & $1.76 \pm 0.10$ \\
\hline $\mathrm{HB}(0.4 \mathrm{mmol} / \mathrm{kg} / \mathrm{d})$ & + & - & $3,168 \pm 625$ & $5,392 \pm 847$ & $1.80 \pm 0.12$ \\
\hline $\mathrm{HB}(0.8 \mathrm{mmol} / \mathrm{kg} / \mathrm{d})$ & + & - & $3,720 \pm 185$ & $7,693 \pm 659$ & $2.00 \pm 0.39$ \\
\hline $\mathrm{HB}(1.6 \mathrm{mmol} / \mathrm{kg} / \mathrm{d})$ & + & - & $6,300 \pm 506^{A}$ & $9,597 \pm 601$ & $3.73 \pm 0.10^{\mathrm{B}}$ \\
\hline$-\mathrm{HB}(1.6 \mathrm{mmol} / \mathrm{kg} / \mathrm{d})$ & + & - & $2,780 \pm 236$ & $7,525 \pm 360$ & $1.10 \pm 0.33$ \\
\hline $\mathrm{HB}(1.6 \mathrm{mmol} / \mathrm{kg} / \mathrm{d})$ & + & + & $1,947 \pm 389$ & $4,627 \pm 701$ & $1.73 \pm 0.27$ \\
\hline
\end{tabular}

Animals with pumps containing either vehicle (saline) or different isoforms of $\beta$-hydroxybutyrate were injected intraperitoneally with MPTP, 3-NP, or saline (not shown). Data represent mean \pm SEM of six to nine mice per group. ${ }^{A} P<0.01$ and ${ }^{B} P<0.05$ compared with the saline-MPTP group. 


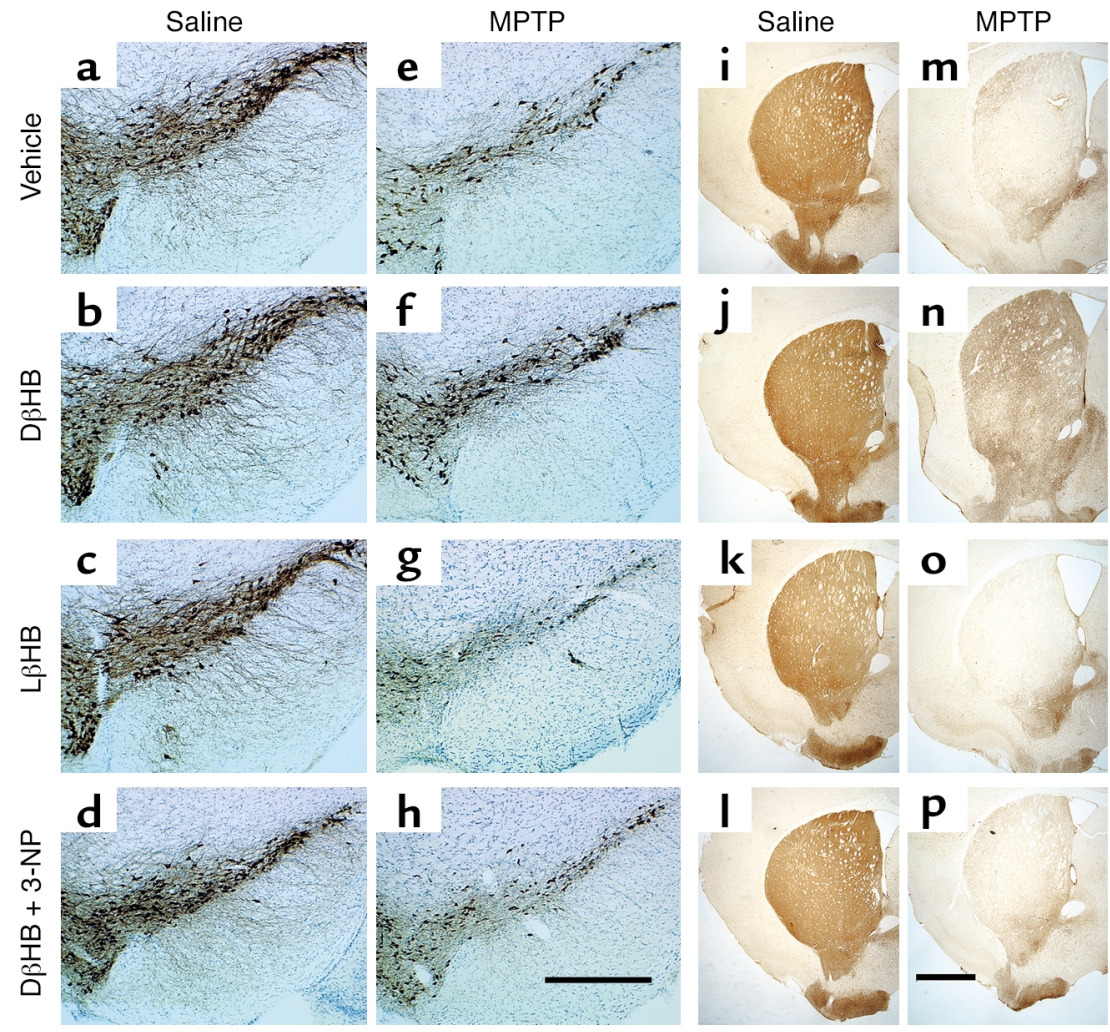

\section{Figure 2}

Protective effect of $\mathrm{D} \beta \mathrm{HB}$ against MPTPinduced neurodegeneration. (a-h) TH-positive neurons in $\mathrm{SNpc}$, and (i-p) TH-positive terminals in striatum. Animals were infused subcutaneously with vehicle (saline; a, e, i, and $\mathbf{m}), D \beta \mathrm{HB}(1.6 \mathrm{mmol} / \mathrm{kg} / \mathrm{d}$; b, $\mathbf{d}, \mathbf{f}, \mathbf{h}, \mathbf{j}, \mathbf{I}, \mathbf{n}$, and $\mathbf{p})$, or $L \beta H B(1.6$ $\mathrm{mmol} / \mathrm{kg} / \mathrm{d} ; \mathbf{c}, \mathbf{g}, \mathbf{k}$, and o) 1 day before receiving intraperitoneal injections of either saline (a-d and $\mathbf{i}-\mathbf{I})$ or MPTP $(18 \mathrm{mg} / \mathrm{kg}$; $\mathbf{e}-\mathbf{h}$ and $\mathbf{m}-\mathbf{p}$ ). There is an extensive loss of $\mathrm{TH}$-positive neurons (e) and terminals (m) in MPTP-injected animals. This loss is attenuated by $\mathrm{D} \beta \mathrm{HB}$ ( $\mathbf{f}$ and $\mathbf{n}$ ) but not by its inactive isomer $L \beta H B$ ( $g$ and $\mathbf{o}$ ). The complex II inhibitor 3-NP was given intraperitoneally $(15 \mathrm{mg} / \mathrm{kg})$ daily for the entire period of $D \beta H B$ infusion. In the presence of 3-NP, $D \beta H B$ does not confer neuroprotection. Scale bars: $500 \mu \mathrm{m}(\mathbf{a}-\mathbf{h})$ and $1 \mathrm{~mm}$ (i-p). Please refer to Table 1 for quantification of neurons and terminals in each animal group. infused with $\mathrm{D} \beta \mathrm{HB}$, less reduction in SNpc TH-positive neurons and striatal TH ODs was observed (Table 1; Figure $2, f$ and $n$ ). To control for the specificity of $D \beta H B$ neuroprotection, another set of MPTP-injected mice received infusion of the inactive isomer $\mathrm{L} \beta \mathrm{HB}$. In these mice, the loss of dopaminergic neurons was as severe as in mice infused with vehicle (Table 1 ; Figure 2 , $g$ and o). Thus, $\mathrm{D} \beta \mathrm{HB}$, but not its inactive isomer, can attenuate neurotoxic effects of MPTP on dopaminergic cell bodies in the SNpc and nerve fibers in the striatum.

$D \beta H B$ attenuates the loss of dopamine and the motor deficit induced by MPTP. To examine whether $\mathrm{D} \beta \mathrm{HB}$ protects not only against structural damage but also against functional deficits caused by MPTP, we assessed levels of dopamine and two of its metabolites, dihydroxyphenylacetic acid (DOPAC) and homovanillic acid (HVA), in ventral midbrain and striatum, as well as locomotor activity, in these animals. In MPTP-injected mice that did not receive $\mathrm{D} \beta \mathrm{HB}$, there was a reduction in dopamine and its metabolites (Table 2) in both ventral midbrain and striatum. Behaviorally, the length of time that these MPTP-injected mice remained on the rotating rods was significantly shorter than that of the saline-injected controls (Figure 3). The motor deficit observed in MPTPtreated mice was alleviated by the administration of L-DOPA/benserazide (data not shown), indicating that this motor deficit results from a loss of dopamine. In MPTP-injected mice that did receive $\mathrm{D} \beta \mathrm{HB}$, the levels of dopamine and its metabolites were all significantly higher than those in MPTP-injected mice that did not receive D $\beta \mathrm{HB}$ (Table 2). Of note, the attenuation of MPTPinduced dopamine loss by $\mathrm{D} \beta \mathrm{HB}$ was smaller than the attenuation of MPTP-induced SNpc neuronal death by D $\beta$ HB. Similarly, MPTP-injected mice that received $\mathrm{D} \beta \mathrm{HB}$ performed much better on the rotating rods than MPTP-injected mice that did not receive $\mathrm{D} \beta \mathrm{HB}$ (Figure 3). Saline-injected mice that received D $\beta H B$ had similar levels of dopamine and metabolites (Table 2) and simi-

Table 2

Levels of dopamine and its metabolites in ventral midbrain and striatal tissues

\begin{tabular}{lcccccc} 
& \multicolumn{3}{c}{ Ventral midbrain levels $(\mathrm{ng} / \mathrm{mg}$ tissue) } & \multicolumn{3}{c}{ Striatal levels (ng/mg tissue) } \\
& DA & DOPAC & HVA & DA & DOPAC & HVA \\
Vehicle & $0.32 \pm 0.01$ & $0.098 \pm 0.003$ & $1.07 \pm 0.02$ & $15.81 \pm 0.69$ & $0.91 \pm 0.06$ & $1.41 \pm 0.03$ \\
D $\beta$ HB & $0.33 \pm 0.02$ & $0.104 \pm 0.010$ & $1.09 \pm 0.11$ & $16.92 \pm 0.53$ & $1.02 \pm 0.01$ & $1.40 \pm 0.11$ \\
Vehicle/MPTP & $0.17 \pm 0.01$ & $0.046 \pm 0.003$ & $0.50 \pm 0.03$ & $0.86 \pm 0.21$ & $0.10 \pm 0.02$ & $0.36 \pm 0.05$ \\
D $\beta$ HB/MPTP & $0.23 \pm 0.01^{\mathrm{A}}$ & $0.070 \pm 0.005^{\mathrm{A}}$ & $0.71 \pm 0.05^{\mathrm{A}}$ & $2.41 \pm 0.45^{\mathrm{B}}$ & $0.24 \pm 0.03^{\mathrm{B}}$ & $0.64 \pm 0.04^{\mathrm{A}}$
\end{tabular}

Animals from the Rotarod study were killed, and their brains were removed and measured by HPLC for the levels of dopamine and its metabolites. Data represent mean \pm SEM of 4-13 mice per group. ${ }^{A} P<0.01 ;{ }^{B} P<0.05$ compared with the MPTP-treated group without $D \beta H B$. 


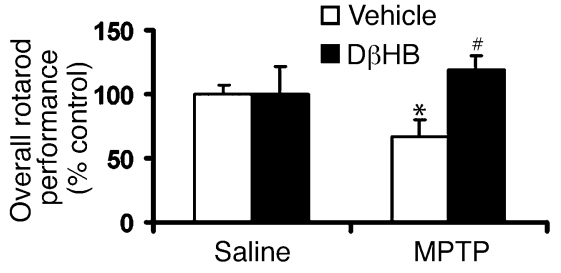

Figure 3

Protective effect of $D \beta H B$ against motor deficit in MPTP-treated mice. Animals were infused subcutaneously with either vehicle (saline) or $\mathrm{D} \beta \mathrm{HB}(1.6 \mathrm{mmol} / \mathrm{kg} / \mathrm{d}) 1$ day before receiving intraperitoneal injections of either saline or MPTP $(18 \mathrm{mg} / \mathrm{kg})$. Pumps were removed at day 7 , and animals were allowed to recover from surgery and dehydration for an additional 7 days before their Rotarod performance was assessed. Motor deficit is observed in the MPTP-treated animals, but $\mathrm{D} \beta \mathrm{HB}$ significantly improves this impairment. $\mathrm{D} \beta \mathrm{HB}$ does not affect base-line motor function in saline-injected mice. $n=4-13 ;{ }^{*} P<0.05$ compared with the saline-vehicle group; ${ }^{\#} P<0.05$ compared with the MPTP-vehicle group.

lar motor performance (Figure 3) to those of salineinjected mice that did not receive $\mathrm{D} \beta \mathrm{HB}$.

$D \beta H B$ does not affect MPTP activation. MPTP is a protoxin whose effect correlates with the striatal content of its active metabolite $\mathrm{MPP}^{+}(30)$. Striatal levels of $\mathrm{MPP}^{+}$ 90 minutes after the last injection of MPTP did not differ between mice that received D $\beta \mathrm{HB}(30.9 \pm 1.6 \mu \mathrm{g} / \mathrm{g}$ tissue) or vehicle $[26.8 \pm 1.3 \mu \mathrm{g} / \mathrm{g}$ tissue; Student's $t$ test with 6 degrees of freedom $(t(6))=1.98 ; P=0.1]$. MPTPinduced dopaminergic neurotoxicity relies on the entry of $\mathrm{MPP}^{+}$into dopaminergic neurons via dopamine transporters (31). D $\beta \mathrm{HB}$ did not impair the uptake of $\left[{ }^{3} \mathrm{H}\right] \mathrm{MPP}^{+}$by striatal synaptosomes at concentrations up to $5 \mathrm{mM}$, which is more than five times the plasma concentration found in $\mathrm{D} \beta \mathrm{HB}$-infused animals (vehicle, $100 \% \pm 2.3 \%$ of control; $\mathrm{D} \beta \mathrm{HB}, 99.1 \% \pm 1.8 \%$ of control; $t(6)=0.3 ; P=0.8)$. Inside dopaminergic neurons, $\mathrm{MPP}^{+}$ is concentrated within mitochondria by a mechanism that depends on mitochondrial $\Delta \psi_{\mathrm{m}}(20)$. At $5 \mathrm{mM}$,
$\mathrm{D} \beta \mathrm{HB}$ did not alter the uptake of $\left[{ }^{3} \mathrm{H}\right] \mathrm{MPP}^{+}$by purified brain mitochondria (vehicle, $100 \% \pm 4.1 \%$ of control; $\mathrm{D} \beta \mathrm{HB}, 93.2 \% \pm 0.5 \%$ of control; $t(6)=1.7 ; P=0.1)$. Thus, it is unlikely that the neuroprotective effect of $\mathrm{D} \beta \mathrm{HB}$ in the MPTP model of PD results from alterations in the key MPTP toxicokinetic steps described above.

$D \beta H B$ increases mitochondrial oxygen consumption. $\mathrm{D} \beta \mathrm{HB}$ has been used as a mitochondrial substrate $(32,33)$. We thus asked whether $\mathrm{D} \beta \mathrm{HB}$ could support oxidative phosphorylation in brain mitochondria, and, if so, whether it may rescue mitochondrial respiration depressed by $\mathrm{MPP}^{+}$-mediated complex I blockade (34). Consistent with $\mathrm{D} \beta \mathrm{HB}$ being a mitochondrial substrate, we found that it increased oxygen consumption in a dose-dependent manner (Figure 4, a and b). The effects of $\mathrm{D} \beta \mathrm{HB}$ in supporting mitochondrial respiration are stereospecific, since the inactive isomer $\mathrm{L} \beta \mathrm{HB}$ failed to improve oxidative phosphorylation (Figure 4c). We also found that $\mathrm{D} \beta \mathrm{HB}$ ameliorated oxygen consumption impaired by different concentrations of $\mathrm{MPP}^{+}$ (Figure 4a) and of another complex I inhibitor, rotenone (Figure $4 \mathrm{~b}$ ). At $25 \mu \mathrm{M} \mathrm{MPP}^{+}$and $25 \mathrm{nM}$ rotenone, which we found to inhibit about $25 \%$ of the oxygen consumption in glutamate- and malate-supported mitochondria, $\mathrm{D} \beta \mathrm{HB}$ restored completely the oxygen consumption depressed by these inhibitors (Figure 4, a and b). At 100 $\mu \mathrm{M} \mathrm{MPP}^{+}$and $100 \mathrm{nM}$ rotenone inhibits more than $90 \%$ of the oxygen consumption in glutamate- and malatesupported mitochondrial respiration (data not shown). At these concentrations, $\mathrm{D} \beta \mathrm{HB}$ restored completely the oxygen consumption inhibited by $\mathrm{MPP}^{+}$, but only partially that inhibited by rotenone (Figure 4 , a and b).

$D \beta H B$ does not uncouple mitochondria. To assure that the increase in rate of oxygen consumption induced by $\mathrm{D} \beta \mathrm{HB}$ is not an artifact of uncoupled mitochondria, we measured $\Delta \psi_{\mathrm{m}}$. As expected, the uncoupler FCCP at 5 $\mu \mathrm{M}$ collapsed the $\Delta \psi_{\mathrm{m}}$ in isolated mitochondria (FCCP, $419 \pm 23$ AFUs; no FCCP, $69 \pm 2$ AFUs). Conversely,

\section{Figure 4}

$\mathrm{D} \beta \mathrm{HB}$ increases oxygen consumption in purified brain mitochondria. Mitochondria $(300 \mu \mathrm{g})$ were incubated in the absence or presence of $\mathrm{MPP}^{+}(5 \mathrm{~min}$ utes; a) or rotenone $(2.5$ minutes; $\mathbf{b})$ at $30^{\circ} \mathrm{C}$, and then $5 \mathrm{mM} \mathrm{D} \beta \mathrm{HB}$ was added to induce oxygen consumption. $\mathrm{D} \beta \mathrm{HB}$ attenuated inhibition of mitochondrial respiration induced by $\mathrm{MPP}^{+}(\mathbf{a})$ or rotenone $(\mathbf{b})$ at indicated concentrations, which blocked about $25-90 \%$ of oxygen consumption when glutamate and malate were used as $\mathrm{NADH}$-linked substrates (data not shown). (c) The improvement of oxygen consumption by $\mathrm{D} \beta \mathrm{HB}$ is stereospecific and is blocked by $10 \mathrm{mM}$ 3-NP, a complex II inhibitor. (d) D $\beta \mathrm{HB}$ increases oxygen consumption in a dose-dependent and saturable fashion as seen with succinate, a complex II substrate, although not as efficiently as succinate does on an equimolar basis. $n=3-4$.
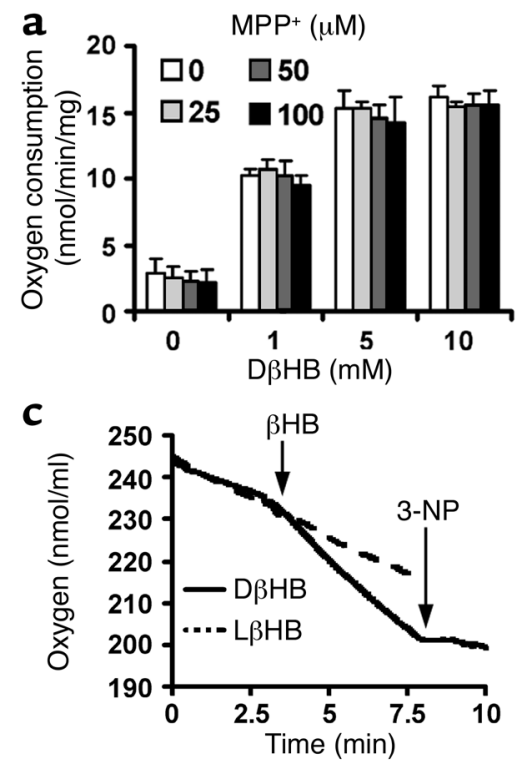
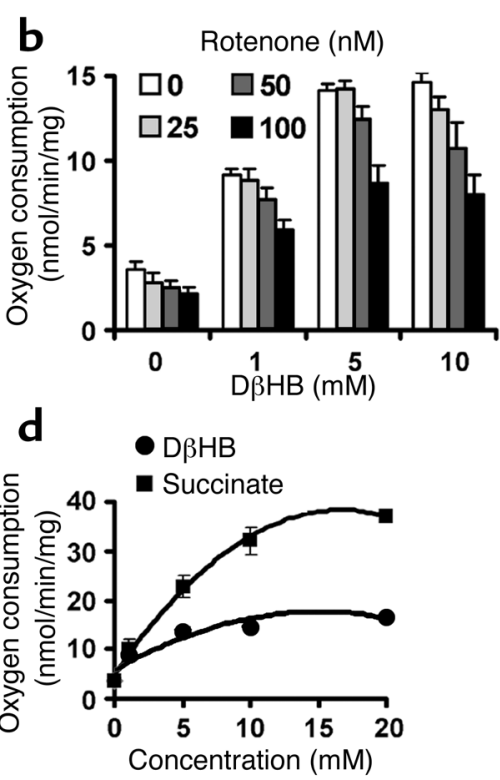


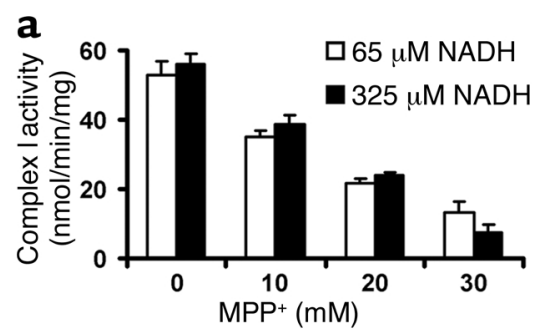

c

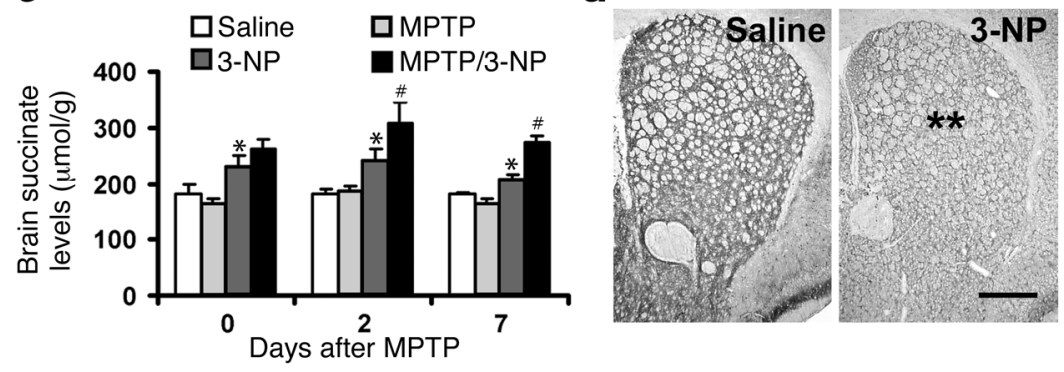

Figure 5

Dose-response study of NADH in complex I activity (a and $\mathbf{b}$ ) and brain levels of succinate (c). In mitochondria lysed by freeze-thawing, when the inhibition of complex I activity was titrated with different concentrations of $\operatorname{MPP}^{+}(\mathbf{a})$ or rotenone (b), different amounts of $\mathrm{NADH}$ did not produce different responses in complex I activity $(n=4$ per group). (c) Levels of succinate were measured in the brains of animals treated with $18 \mathrm{mg} / \mathrm{kg} / \mathrm{d}$ MPTP or $15 \mathrm{mg} / \mathrm{kg} 3-\mathrm{NP}$, or both. Levels of succinate in the group that received $\mathrm{D} \beta \mathrm{HB}(1.6$ $\mathrm{mmol} / \mathrm{kg} / \mathrm{d}$ ) are significantly increased in the presence of 3-NP. $n=3-10$ per group; ${ }^{*} P<0.05$ compared with the control saline group; $P<0.05$ compared with the 3 -NP group. (d) Histochemical analysis in striatal sections shows that when animals were treated with 3-NP (right panel) at this concentration for 8 days, there was approximately $40 \%$ reduction in complex II activity in the striatum compared with that in the group treated with saline (left panel). $n=5$ per group; ${ }^{*} P<0.01$. Scale bar: $500 \mu \mathrm{m}$.

$\mathrm{D} \beta \mathrm{HB}$ at concentrations as high as $5 \mathrm{mM}$ had no effect on mitochondrial $\Delta \psi_{\mathrm{m}}(\mathrm{D} \beta \mathrm{HB}, 68.58 \pm 3.07$ AFUs; no $\mathrm{D} \beta \mathrm{HB}, 65.21 \pm 3.03 \mathrm{AFUs} ; n=5$ per group; $P>0.05$ ). We also found that the increase in oxygen-consumption rate produced by $\mathrm{D} \beta \mathrm{HB}$ could be blocked by antimycin A, a complex III inhibitor (base line, $4.49 \pm 0.62$ $\mathrm{nmol} / \mathrm{min} / \mathrm{mg}$; $\mathrm{D} \beta \mathrm{HB}, 14.14 \pm 0.43 \mathrm{nmol} / \mathrm{min} / \mathrm{mg}$; $\mathrm{D} \beta \mathrm{HB}+$ antimycin A, $5.99 \pm 0.95 \mathrm{nmol} / \mathrm{min} / \mathrm{mg} ; n=3$ per group; $P>0.05$ comparing base line with the $\mathrm{D} \beta \mathrm{HB}+$ antimycin A group). These experiments indicate that $\mathrm{D} \beta \mathrm{HB}$ does not uncouple mitochondria at concentrations that increased oxygen consumption.

Effects of $D \beta H B$ on mitochondrial respiration seem driven by complex II. One product generated from the metabolism of $\mathrm{D} \beta \mathrm{HB}$ is $\mathrm{NADH}$, which provides the driving force for the mitochondrial respiration through complex I. Can an increase in availability of NADH compensate for the loss of oxygen consumption due to complex I inhibition? To test this possibility, freeze-thawed disrupted brain mitochondria were incubated with $\mathrm{MPP}^{+}$, or rotenone, and $\mathrm{NADH}$. Concentrations of $\mathrm{MPP}^{+}$and rotenone were selected to produce complex I inhibition ranging from about $40 \%$ to $100 \%$, and supplementation of $\mathrm{NADH}$ ranged from 0.5 to 2.5 times the normal concentration used in the assay (Figure 5, a and b). These changes in $\mathrm{NADH}$ supplementation did not modify the degree of complex I inhibition (Figure 5, a and b). This indicates that D $\beta$ HB-derived NADH cannot explain the improvement seen in mitochondrial respiration produced by $\mathrm{D} \beta \mathrm{HB}$.

Based on its metabolic pathway, $\mathrm{D} \beta \mathrm{HB}$ can also generate succinate, which is capable of stimulating the rate of oxygen consumption in isolated brain mitochondria through complex II. In keeping with this metabolic pathway, we found that both $\mathrm{D} \beta \mathrm{HB}$ and succinate did improve oxygen consumption in a dose-dependent and saturable manner, although $\mathrm{D} \beta \mathrm{HB}$ was not as potent as succinate (Figure $4 \mathrm{~d}$ ). This is not unexpected, since $\mathrm{D} \beta \mathrm{HB}$ has to go through several metabolic steps to generate succinate. In addition, we found that the beneficial effects of $\mathrm{D} \beta \mathrm{HB}$ on mitochondrial respiration in the presence of $\mathrm{MPP}^{+}$or rotenone were completely abolished by two different complex II inhibitors, 3-NP at $10 \mathrm{mM}$ (Figure 4c) and malonate at $10 \mathrm{mM}$ (data not shown). Together, these data are consistent with the idea that $\mathrm{D} \beta \mathrm{HB}$ increases mitochondrial respiration in the face of complex I inhibition by a complex II-dependent mechanism.

$D \beta H B$ neuroprotection is abrogated by mitochondrial complex II inbibition in vivo. To determine whether our in vitro data are relevant to $\mathrm{D} \beta \mathrm{HB}$ neuroprotection seen in vivo, we first measured succinate levels in the brains of D $\beta$ HB-infused mice. Upon inhibition of complex II, $\mathrm{D} \beta \mathrm{HB}$ infusion indeed increased levels of succinate in the brain (Figure 5c). Next, MPTP-injected mice infused with $D \beta H B$ were injected with 3-NP. This irreversible complex II inhibitor was administered daily for the entire period of $\mathrm{D} \beta \mathrm{HB}$ infusion at a dosage of 15 $\mathrm{mg} / \mathrm{kg} / \mathrm{d}$. As illustrated in Figure $5 \mathrm{~d}$, this regimen of 3 -NP inhibited approximately $40 \%$ of complex II activi-

\section{Table 3}

ATP levels in purified brain mitochondria

ATP levels ( $\mathrm{nmol} / \mathrm{mg}$ mitochondrial protein) Base line (no substrate)

$\mathrm{D} \beta \mathrm{HB}(5 \mathrm{mM})$

$\mathrm{D} \beta \mathrm{HB}$ plus $\mathrm{MPP}^{+}(100 \mu \mathrm{M})$

$\mathrm{D} \beta \mathrm{HB}$ plus rotenone $(100 \mathrm{nM})$

$\mathrm{D} \beta \mathrm{HB}$ plus $\mathrm{MPP}^{+}$plus 3-NP $(10 \mathrm{mM})$

$\mathrm{D} \beta \mathrm{HB}$ plus rotenone plus 3-NP

$L \beta \mathrm{HB}$

$\begin{aligned} 5.37 & \pm 0.30 \\ 76.16 & \pm 6.11^{\mathrm{A}} \\ 90.49 & \pm 9.73^{\mathrm{A}} \\ 25.96 & \pm 5.22^{\mathrm{B}} \\ 0.62 & \pm 0.21 \\ 0.73 & \pm 0.23 \\ 3.85 & \pm 0.24\end{aligned}$

Mitochondrial samples were prepared as in the polarographical studies, and ATP levels were measured using a luciferase kit. Data represent mean \pm SEM of four mice per group. ${ }^{A} P<0.01$ and ${ }^{B} P<0.05$ compared with the base-line endogenous ATP level. 


\section{Table 4}

$\mathrm{H}_{2} \mathrm{O}_{2}$ measurements in purified brain mitochondria

Treatment

$\mathrm{D} \beta \mathrm{HB}(5 \mathrm{mM})$

Rotenone (100 nM)

$\mathrm{D} \beta \mathrm{HB}$ plus rotenone

$\mathrm{D} \beta \mathrm{HB}$ plus rotenone plus 3-NP $(10 \mathrm{mM})$

$\mathrm{D} \beta \mathrm{HB}$ plus rotenone plus $\mathrm{PM}(0.1 \mathrm{mM})$

$\mathrm{L} \beta \mathrm{HB}(5 \mathrm{mM})$ plus rotenone

$\mathrm{MPP}^{+}(500 \mu \mathrm{M})$

$\mathrm{D} \beta \mathrm{HB}$ plus $\mathrm{MPP}^{+}$

$\mathrm{D} \beta \mathrm{HB}$ plus $\mathrm{MPP}^{+}$plus PM

L $\beta$ HB plus MPP ${ }^{+}$
Mitochondrial $\mathrm{H}_{2} \mathrm{O}_{2}$ production (pmol/min/mg protein)

$73.83 \pm 8.04$

$132.39 \pm 19.68$

$506.00 \pm 40.47^{\mathrm{A}}$

$522.76 \pm 62.23^{\mathrm{A}}$

$160.50 \pm 20.62$

$105.91 \pm 7.45$

$55.24 \pm 12.98$

$94.92 \pm 6.79^{\mathrm{B}}$

$73.76 \pm 6.38$

$54.28 \pm 4.93$

Mitochondrial samples similar to those in the polarographical studies were prepared, and the fluorescence dye Amplex red was used to measure $\mathrm{H}_{2} \mathrm{O}_{2}$ converted from superoxide. Data represent mean \pm SEM of four mice per group. ${ }^{A} P<0.01$ compared with the rotenone-alone group; ${ }^{B} P<0.05 \mathrm{com}$ pared with the $\mathrm{MPP}^{+}$-alone group. $\mathrm{PM}$, phenazine methosulfate.

ty in the striatum without causing cell death in either the SNpc (Table 1) or the striatum, as evidenced by TH or Nissl staining (Table 1; data not shown for striatal Nissl staining). As before, D $\beta \mathrm{HB}$ protected against MPTP neurotoxicity in mice that did not receive 3-NP. However, D $\beta$ HB failed to reduce MPTP-induced dopaminergic neurodegeneration in mice that did receive 3-NP (Table 1; Figure 2, h and p). Supporting the effectiveness of the 3-NP regimen in blocking complex II is our demonstration that succinate levels in the brain were higher in mice that received 3-NP than in those that did not (Figure 5c). Thus, these results are consistent with the hypothesis that complex II is a pivotal mediator in D $\beta$ HB's neuroprotective effects.

$D \beta H B$ does not have antioxidant effects but increases ATP production. Inhibition of complex I by $\mathrm{MPP}^{+}$and rotenone generates reactive oxygen species (ROS), raising the possibility that the beneficial effects of $\mathrm{D} \beta \mathrm{HB}$ are mediated by an antioxidant action, as previously suggested (14). In isolated mitochondria, $\mathrm{D} \beta \mathrm{HB}$ did not reduce but stimulated ROS production in the presence of rotenone or $\mathrm{MPP}^{+}$ (see Table 4). To elucidate the basis of D $\beta$ HB-related ROS production, 3-NP was added to the incubation mixture (see Table 4). This complex II inhibitor was unable to block the $\mathrm{D} \beta \mathrm{HB}$-related ROS production, thus ruling out the possibility of a reversed flux of electrons from complex II to complex I as the ROS generator $(22,23)$. Instead, we suspected that the $\mathrm{D} \beta \mathrm{HB}$-related ROS resulted from additional NADH generated by $\mathrm{D} \beta \mathrm{HB}$ metabolism. To test this alternative possibility, phenazine methosulfate, a compound that oxidizes NADH (21), was included in the incubation mixture. Consistent with this possibility, phenazine methosulfate abolished ROS production (see Table 4). These data argue against D $\beta H B$ having antioxidant properties, at least in this in vitro setting.

Inhibition of complex I by $\mathrm{MPP}^{+}$and rotenone also impairs ATP production, raising the possibility that the beneficial effects of $\mathrm{D} \beta \mathrm{HB}$ are mediated by attenuation of ATP depletion. We thus measured ATP production in

isolated brain mitochondria under conditions similar to those of polarographical study. As shown in Table 3, $\mathrm{D} \beta \mathrm{HB}$ increased ATP production from a base line of $5.37 \pm 0.30 \mathrm{nmol} / \mathrm{mg}$ protein to $76.16 \pm 6.11 \mathrm{nmol} / \mathrm{mg}$ protein. The increase of ATP production was not detected with the inactive isomer $\mathrm{L} \beta \mathrm{HB}(3.85 \pm 0.24 \mathrm{nmol} / \mathrm{mg}$ protein). In agreement with the oxygen-consumption data, $\mathrm{D} \beta \mathrm{HB}$ prevented the loss of ATP production caused by $100 \mu \mathrm{M} \mathrm{MPP}^{+}$or $100 \mathrm{nM}$ rotenone (Table 3 ). Yet, upon addition of $3-\mathrm{NP}, \mathrm{D} \beta \mathrm{HB}$-related ATP production was abolished (Table 3 ). Together, these data are consistent with the contention that the effects of $\mathrm{D} \beta \mathrm{HB}$ seen in the polarographical studies correspond to an increase in oxidative phosphorylation.

\section{Discussion}

The present study shows that the ketone body $\mathrm{D} \beta \mathrm{HB}$, a crucial alternative source of glucose for brain energy, confers protection against the structural and functional deleterious effects of the parkinsonian toxin MPTP; these include degeneration of SNpc dopaminergic neurons and striatal dopaminergic fibers, loss of striatal dopamine, and PD-like motor deficit. The beneficial effects of $\mathrm{D} \beta \mathrm{HB}$ were achieved by its subcutaneous infusion using osmotic mini-osmotic pumps, which, without apparent distress, allowed its reliable continuous delivery to the brain. While $\mathrm{D} \beta \mathrm{HB}$ levels in the brain were stable in D $\beta$ HB-infused mice exposed to MPTP, in mice injected with saline they were higher at the beginning and then dropped during the experimental period of 7 days. Although the basis for these differences remains to be elucidated, it is possible that the utilization of $\mathrm{D} \beta \mathrm{HB}$ in the brain increases rapidly following exposure to mitochondrial poisons such as MPTP and augments progressively in normal brain as part of a metabolic adaptation to sustained high $\mathrm{D} \beta \mathrm{HB}$ concentrations.

Utilization of $\mathrm{D} \beta \mathrm{HB}$ in the brain is contingent on its conversion to acetoacetate by $\beta$-hydroxybutyrate dehydrogenase, which is scarce in the adult brain, especially in the basal ganglia (35). The activity of $\beta$-hydroxybutyrate dehydrogenase correlates with its protein content (36), and, following MPTP administration, it is upregulated in the ventral midbrain. MPTP-induced $\beta$-hydroxybutyrate dehydrogenase upregulation precedes peak dopaminergic neuronal death in this model (37). It can thus be envisioned that $\beta$-hydroxybutyrate dehydrogenase activity increases early enough to allow effective utilization of $\mathrm{D} \beta \mathrm{HB}$ by the compromised dopaminergic neurons.

A critical step in activation of MPTP is its conversion into $\mathrm{MPP}^{+}$by monoamine oxidase (38). The possibility that $\mathrm{D} \beta \mathrm{HB}$ infusion confers protection by interfering with monoamine oxidase activity can be ruled out given the fact that brain levels of $\mathrm{MPP}^{+}$were similar between mice that received and those that did not receive $\mathrm{D} \beta \mathrm{HB}$. Also arguing against the possibility that $\mathrm{D} \beta \mathrm{HB}$ confers protection by impairing MPTP activation is the fact that $\mathrm{D} \beta \mathrm{HB}$ attenuates dopaminergic neuronal death in primary ventral midbrain cultures exposed to $\mathrm{MPP}^{+}(14)$. $\mathrm{D} \beta \mathrm{HB}$ also did not interfere with other key aspects of 
MPTP metabolism (39), such as entry of $\mathrm{MPP}^{+}$into dopaminergic neurons and mitochondria at concentrations as high as $5 \mathrm{mM}$. Together these data indicate that $\mathrm{D} \beta \mathrm{HB}$ protects not by a pre-complex I mechanism but rather by mitigating the deleterious effects of complex I inhibition on the survival of dopaminergic neurons.

In isolated brain mitochondria, $\mathrm{D} \beta \mathrm{HB}$ improves oxygen consumption in the presence of the complex I poisons $\mathrm{MPP}^{+}$and rotenone. The $\mathrm{D} \beta \mathrm{HB}$ effect is dose dependent and stereospecific. The metabolism of $\mathrm{D} \beta \mathrm{HB}$ leads to an elevated mitochondrial $[\mathrm{NADH}] /\left[\mathrm{NAD}^{+}\right]$ratio due to NADH generated from the conversion of $\mathrm{D} \beta \mathrm{HB}$ to acetoacetate and also from the tricarboxylic acid (TCA) cycle, whose turnover is increased by high levels of acetylCoA produced by acetoacetate. NADH is used by complex I to drive mitochondrial respiration. $\mathrm{D} \beta \mathrm{HB}$ may increase oxygen consumption by fueling mitochondria with NADH. However, in the presence of complex I inhibition by $\mathrm{MPP}^{+}$or rotenone, $\mathrm{NADH}$ oxidation is impaired and, as shown in this study, an increase in NADH content is unable to alleviate complex I blockade.

In addition to generating $\mathrm{NADH}$, increased TCA turnover, in theory, should also lead to increases in production of other TCA intermediates such as succinate. Here, we show that $\mathrm{D} \beta \mathrm{HB}$ infusion does increase brain succinate content. While succinate is a TCA cycle substrate, its oxidation by succinate dehydrogenase is coupled to a transfer of electrons to ubiquinone of the mitochondrial respiratory chain, and thus succinate is routinely used to support oxygen consumption in the presence of complex I blockade. We demonstrate that inhibition of complex II (a) abrogates D $\beta$ HB-mediated increases in oxygen consumption in isolated mitochondria and (b) abolishes $\mathrm{D} \beta \mathrm{HB}$-mediated protective effects on SNpc dopaminergic neurons and striatal dopaminergic fibers after MPTP administration. Thus, these data strongly support our hypothesis that the beneficial effect of $\mathrm{D} \beta \mathrm{HB}$ in the MPTP model of PD involves a complex II-dependent mechanism.

It has been proposed that the ability of $\mathrm{D} \beta \mathrm{HB}$ to decrease $\mathrm{MPP}^{+}$neurotoxicity in primary ventral midbrain cultures is related to the oxidation of the coenzyme Q couple, which should, by decreasing the semiquinone, decrease ROS production (14). Contrary to this prediction, we found, at least in isolated mitochondria, that rather than decreasing ROS production induced by $\mathrm{MPP}^{+}$ or rotenone, $\mathrm{D} \beta \mathrm{HB}$ enhanced it even further. These findings cast doubt that $\mathrm{D} \beta \mathrm{HB}$ protects the nigrostriatal pathway through an antioxidant mechanism. How can $\mathrm{D} \beta \mathrm{HB}$ increase ROS? Succinate is the most effective ROS-generating substrate in intact brain mitochondria $(22,23)$, by stimulating a reversed flux of electrons from complex II to complex I $(22,23)$. However, rotenone blocks this ROS signal $(22,23)$; thus, in the context of the present study, in which complex I is inhibited, this mechanism may not be operative. Instead, our data suggest that $\mathrm{D} \beta \mathrm{HB}$-derived NADH, by feeding complex I, increases the accumulation of electrons upstream to the blockade, thereby stimulating ROS production.
Mitochondrial respiration is tightly linked to ATP synthesis (40). It may thus be speculated that $\mathrm{D} \beta \mathrm{HB}$, by restoring oxygen consumption in MPTP-intoxicated animals, may increase ATP cellular stores. Ablation and inhibition of poly(ADP-ribose) polymerase-1 $(41,42)$ and creatine supplements (43) mitigate MPTP-induced death of dopaminergic neurons in the SNpc by buffering ATP depletion. These studies underscore the importance of ATP deficit in the MPTP neurodegenerative process. In normal rodents, dopaminergic structures represent less than $15 \%$ of the cellular elements in the striatum (44) and hardly more in the ventral midbrain. This renders precarious any detection of ATP changes in brain tissues of MPTP-intoxicated mice (45). To avoid this problem, we studied the effects of $\mathrm{D} \beta \mathrm{HB}$ on ATP production in isolated brain mitochondria. By this approach, we were able to demonstrate that $\mathrm{D} \beta \mathrm{HB}$ does increase ATP levels in both the absence and the presence of complex I inhibitors. Consistent with the oxygen-consumption data, we also found that the stimulation of ATP production by $\mathrm{D} \beta \mathrm{HB}$ likely relies on complex II, as inhibitors of this electron transport chain enzyme eliminated the effect. Data generated in isolated mitochondria may only approximate the more complex situation found in vivo. Despite this caveat, we believe that the most parsimonious explanation for $\mathrm{D} \beta \mathrm{HB}$-induced neuroprotection in the MPTP model of PD is that energy crisis is attenuated by an enhancement of oxidative phosphorylation. It is thus tempting to conclude that, under the current $\mathrm{D} \beta \mathrm{HB}$ regimen, the benefit due to the improved ATP production overcomes the possible detriment due to the increased ROS formation in this PD model.

The present study demonstrates that modulation of body $\mathrm{D} \beta \mathrm{HB}$ levels may be a straightforward neuroprotective strategy for the treatment of neurodegenerative diseases such as PD. Relevant to this view is the demonstration that mice subjected to dietary restriction (e.g., alternate-day fasting) exhibit higher serum $\mathrm{D} \beta \mathrm{HB}$ concentrations and are more resistant to kainic acidinduced hippocampus damage (46) and to MPTPinduced SNpc damage (47). At this point, however, the long-term effects of the chronic use of $\mathrm{D} \beta \mathrm{HB}$ on the cell metabolism and, especially, on the mitochondrial function are not known. $\mathrm{D} \beta \mathrm{HB}$ has been administered orally for several months to two 6-month-old infants with hyperinsulinemic hypoglycemia (48). Despite the high dosage (up to $32 \mathrm{~g} / \mathrm{d}$ ), these patients seem to tolerate quite well. In addition, the ketogenic diets, which result in high levels of $\mathrm{D} \beta \mathrm{HB}$, have been used for more than 70 years in humans as a treatment for refractory epilepsy and have proven safe and well tolerated.

\section{Acknowledgments}

We wish to thank Andrew Marks (Columbia University) for his generous gift of the antibody against $\beta$-hydroxybutyrate dehydrogenase, Norma Romero for her assistance in animal care, and Soliman Bakr for his assistance in the measurement of succinate and of $\mathrm{D} \beta \mathrm{HB}$, Salvatore DiMauro (Columbia University), 
Richard L. Veech (NIH), Ian J. Reynolds (University of Pittsburgh, Pittsburgh, Pennsylvania, USA), and Gary Fiskum (University of Maryland, Baltimore, Maryland, USA), for their insightful comments on this manuscript. This study is supported by NIH/National Institute of Neurological Disorders and Stroke grants R29 NS37345, R01 NS38586, R01 NS42269, P50 NS38370, and P01 NS11766-27A1; US Department of Defense grants DAMD 17-99-1-9471 and DAMD 17-03-1; the Lowenstein Foundation; the Lillian Goldman Charitable Trust; and the Parkinson's Disease Foundation. P. Teismann is the recipient of grant TE 343/1-1 from the German Research Foundation.

1. Przedborski, S., Vila, M., and Jackson-Lewis, V. 2003. Neurodegeneration: what is it and where are we? J. Clin. Invest. 111:3-10. doi:10.1172/ JCI200317522.

2. Fahn, S., and Przedborski, S. 2000. Parkinsonism. In Merritt's neurology. L.P. Rowland, editor. Lippincott Williams \& Wilkins. New York, New York, USA. 679-693.

3. Przedborski, S., Kostic, V., Giladi, N., and Eidelberg, D. 2003. Dopaminergic system in Parkinson's disease. In Dopamine receptors and transporters. A. Sidhu, M. Laruelle, and P. Vernier, editors. Marcel Dekker Inc. New York, New York, USA. 363-402.

4. Nicklas, W.J., Yougster, S.K., Kindt, M.V., and Heikkila, R.E. 1987. MPTP, $\mathrm{MPP}+$ and mitochondrial function. Life Sci. 40:721-729.

5. Langston, J.W., Ballard, P., and Irwin, I. 1983. Chronic parkinsonism in humans due to a product of meperidine-analog synthesis. Science. 219:979-980.

6. Greenamyre,J.T., Sherer, T.B., Betarbet, R., and Panov, A.V. 2001. Complex I and Parkinson's disease. IUBMB Life. 52:135-141.

7. Schapira, A.H., et al. 1990. Mitochondrial complex I deficiency in Parkinson's disease. J. Neurochem. 54:823-827.

8. Parker, W.D., Jr., Boyson, S.J., and Parks, J.K. 1989. Abnormalities of the electron transport chain in idiopathic Parkinson's disease. Ann. Neurol. 26:719-723.

9. Haas, R.H., et al. 1995. Low platelet mitochondrial complex I and complex II/III activity in early untreated Parkinson's disease. Ann. Neurol. 37:714-722.

10. Swerdlow, R.H., et al. 1996. Origin and functional consequences of the complex I defect in Parkinson's disease. Ann. Neurol. 40:663-671.

11. Guzman, M., and Blazquez, C. 2001. Is there an astrocyte-neuron ketone body shuttle? Trends Endocrinol. Metab. 12:169-173.

12. Owen, O.E., et al. 1967. Brain metabolism during fasting. J. Clin. Invest. 46:1589-1595.

13. Izumi, Y., Ishii, K., Katsuki, H., Benz, A.M., and Zorumski, C.F. 1998. $\beta$-Hydroxybutyrate fuels synaptic function during development. Histological and physiological evidence in rat hippocampal slices. J. Clin. Invest. 101:1121-1132.

14. Kashiwaya, Y., et al. 2000. D-beta-hydroxybutyrate protects neurons in models of Alzheimer's and Parkinson's disease. Proc. Natl. Acad. Sci. U. S. A. 97:5440-5444.

15. Liberatore, G., et al. 1999. Inducible nitric oxide synthase stimulates dopaminergic neurodegeneration in the MPTP model of Parkinson's disease. Nat. Med. 5:1403-1409.

16. Teismann, P., et al. 2003. Cyclooxygenase-2 is instrumental in Parkinson's disease neurodegeneration. Proc. Natl. Acad. Sci. U. S. A. 100:5473-5478.

17. Yan, S.D., et al. 2000. Amyloid beta-peptide-binding alcohol dehydrogenase is a component of the cellular response to nutritional stress. J. Biol. Chem. 275:27100-27109.

18. Przedborski, S., et al. 1996. Role of neuronal nitric oxide in MPTP (1-methyl4-phenyl-1,2,3,6-tetrahydropyridine)-induced dopaminergic neurotoxicity. Proc. Natl. Acad. Sci. U. S. A. 93:4565-4571.

19. Przedborski, S., et al. 1992. Transgenic mice with increased $\mathrm{Cu} / \mathrm{Zn}$-superoxide dismutase activity are resistant to $\mathrm{N}$-methyl-4-phenyl-1,2,3,6-tetrahydropyridine-induced neurotoxicity. J. Neurosci. 12:1658-1667.

20. Ramsay, R.R., and Singer, T.P. 1986. Energy-dependent uptake of N-methyl4-phenylpyridinium, the neurotoxic metabolite of 1-methyl-4-phenyl1,2,3,6-tetrahydropyridine, by mitochondria. J. Biol. Chem. 261:7585-7587.

21. Vyas, I., Heikkila, R.E., and Nicklas, W.J. 1986. Studies on the neurotoxicity of 1-methyl-4-phenyl-1,2,3,6-tetrahydropyridine: inhibition of NAD-linked substrate oxidation by its metabolite, 1-methyl-4-phenylpyridinium. J. Neurochem. 46:1501-1507.

22. Liu, Y., Fiskum, G., and Schubert, D. 2002. Generation of reactive oxygen species by the mitochondrial electron transport chain. J. Neurochem. 80:780-787.
23. Votyakova, T.V., and Reynolds, I.J. 2001. DeltaPsi(m)-dependent and -independent production of reactive oxygen species by rat brain mitochondria. J. Neurochem. 79:266-277.

24. Birch-Machin, M.A., and Turnbull, D.M. 2001. Assaying mitochondrial respiratory complex activity in mitochondria isolated from human cells and tissues. Methods Cell Biol. 65:97-117.

25. Brouillet, E., et al. 1998. Partial inhibition of brain succinate dehydrogenase by 3-nitropropionic acid is sufficient to initiate striatal degeneration in rat. J. Neurochem. 70:794-805.

26. Vila, M., et al. 2001. Bax ablation prevents dopaminergic neurodegeneration in the 1-methyl- 4-phenyl-1,2,3,6-tetrahydropyridine mouse model of Parkinson's disease. Proc. Natl. Acad. Sci. U. S. A. 98:2837-2842.

27. Rozas, G., López-Martín, E., Guerra, M.J., and Labandeira-García,J.L. 1998. The overall rod performance test in the MPTP-treated-mouse model of Parkinsonism. J. Neurosci. Methods. 83:165-175.

28. Wallace, T.M., Meston, N.M., Gardner, S.G., and Matthews, D.R. 2001. The hospital and home use of a 30-second hand-held blood ketone meter: guidelines for clinical practice. Diabet. Med. 18:640-645.

29. Sokoloff, L. 1973. Metabolism of ketone bodies by the brain. Annu. Rev. Med. 24:271-280.

30. Giovanni, A., Sieber, B.A., Heikkila, R.E., and Sonsalla, P.K. 1991. Correlation between the neostriatal content of the 1-methyl-4-phenylpyridinium species and dopaminergic neurotoxicity following 1-methyl-4-phenyl1,2,3,6-tetrahydropyridine administration to several strains of mice. J. Pharmacol. Exp. Ther. 257:691-697.

31. Javitch, J.A., D’Amato, R.J., Strittmatter, S.M., and Snyder, S.H. 1985. Parkinsonism-inducing neurotoxin, N-methyl-4-phenyl-1,2,3,6-tetrahydropyridine: uptake of the metabolite $\mathrm{N}$-methyl-4-phenylpyridinium by dopamine neurons explains selective toxicity. Proc. Natl. Acad. Sci. U. S. A. 82:2173-2177.

32. Brown, G.C., Lakin-Thomas, P.L., and Brand, M.D. 1990. Control of respiration and oxidative phosphorylation in isolated rat liver cells. Eur. J. Biochem. 192:355-362.

33. Lai, J.C., and Clark, J.B. 1979. Preparation of synaptic and nonsynaptic mitochondria from mammalian brain. Methods Enzymol. 55:51-60.

34. Nicklas, W.J., Vyas, I., and Heikkila, R.E. 1985. Inhibition of NADH-linked oxidation in brain mitochondria by MPP+, a metabolite of the neurotoxin MPTP. Life Sci. 36:2503-2508.

35. Bilger, A., and Nehlig, A. 1992. Quantitative histochemical changes in enzymes involved in energy metabolism in the rat brain during postnatal development. II. Glucose-6-phosphate dehydrogenase and beta-hydroxybutyrate dehydrogenase. Int. J. Dev. Neurosci. 10:143-152.

36. Zhang, W.W., Churchill, S., and Churchill, P. 1989. Developmental regulation of D-beta-hydroxybutyrate dehydrogenase in rat liver and brain. FEBS Lett. 256:71-74.

37. Jackson-Lewis, V., Jakowec, M., Burke, R.E., and Przedborski, S. 1995. Time course and morphology of dopaminergic neuronal death caused by the neurotoxin 1-methyl-4-phenyl-1,2,3,6-tetrahydropyridine. Neurodegeneration. 4:257-269.

38. Heikkila, R.E., Manzino, L., Cabbat, F.S., and Duvoisin, R.C. 1984. Protection against the dopaminergic neurotoxicity of 1-methyl-4-phenyl-1,2,3,6tetrahydropyridine by monoamine oxidase inhibitors. Nature. 311:467-469.

39. Przedborski, S., and Vila., M. 2003. The 1-methyl-4-phenyl-1,2,3,6-tetrahydropyridine mouse model: a tool to explore the pathogenesis of Parkinson's disease. Ann. N. Y. Acad. Sci. 991:189-198.

40. Brown, G.C. 1992. Control of respiration and ATP synthesis in mammalian mitochondria and cells. Biochem. J. 284:1-13.

41. Mandir, A.S., et al. 1999. Poly (ADP-ribose) polymerase activation mediates MPTP-induced parkinsonism. Proc. Natl. Acad. Sci. U. S. A. 96:5774-5779.

42. Cosi, C., and Marien, M. 1998. Decreases in mouse brain NAD+ and ATP induced by 1-methyl-4-phenyl-1,2,3,6-tetrahydropyridine (MPTP): prevention by the poly(ADP-ribose) polymerase inhibitor, benzamide. Brain Res. 809:58-67.

43. Matthews, R.T., et al. 1999. Creatine and cyclocreatine attenuate MPTP neurotoxicity. Exp. Neurol. 157:142-149.

44. Tennyson, V.M., Heikkila, R., Mytilineou, C., Cote, L., and Cohen, G. 1974. 5-Hydroxydopamine 'tagged' neuronal boutons in rabbit neostriatum: interrelationship between vesicles and axonal membrane. Brain Res. 82:341-348.

45. Chan, P., DeLanney, L.E., Irwin, I., Langston, J.W., and Di Monte, D. 1991. Rapid ATP loss caused by 1-methyl-4-phenyl-1,2,3,6-tetrahydropyridine in mouse brain. J. Neurochem. 57:348-351.

46. Anson, R.M., et al. 2003. Intermittent fasting dissociates beneficial effects of dietary restriction on glucose metabolism and neuronal resistance to injury from calorie intake. Proc. Natl. Acad. Sci. U. S. A. 100:6216-6220.

47. Duan, W., and Mattson, M.P. 1999. Dietary restriction and 2-deoxyglucose administration improve behavioral outcome and reduce degeneration of dopaminergic neurons in models of Parkinson's disease. J. Neurosci. Res. 57:195-206.

48. Plecko, B., et al. 2002. Oral beta-hydroxybutyrate supplementation in two patients with hyperinsulinemic hypoglycemia: monitoring of beta-hydroxybutyrate levels in blood and cerebrospinal fluid, and in the brain by in vivo magnetic resonance spectroscopy. Pediatr. Res. 52:301-306. 